\title{
Resenha de: Brown, M. Leann, 2018. Regional Economic Organizations and Conventional Security Challenges. Gewerbestrasse: Palgrave Macmillan. ISBN: 978-3-319-70533-0.
}

\section{GUILHERME ZIEBELL DE OLIVEIRA}

Ao longo do século XX, especialmente no contexto pós-Segunda Guerra Mundial, assistiu-se a uma proliferação de organizações regionais pelo mundo. Grande parcela dessas organizações tinha como objetivo central fomentar — de forma mais ou menos direta - o desenvolvimento e a integração econômica de seus Estados-membros. Com o encerramento da Guerra Fria, contudo, tais organizações ampliaram progressivamente seu escopo de atuação, passando a assumir a responsabilidade pela garantia da segurança e da estabilidade em suas respectivas regiões. Mas quais seriam os motivos para que as organizações regionais de natureza econômica adotassem funções de segurança convencional? É justamente isso que o livro Regional Economic Organizations and Conventional Security Challenges, da professora de Ciência Política da Universidade da Flórida, M. Leann Brown, busca discutir.

Para construir seu argumento, Brown inicia a obra com uma discussão teórica a respeito dos fatores que levariam a mudanças nas organizações regionais, e que poderiam estar na origem da incorporação, por elas, de funções securitárias. Apoiando-se na revisão de diversos trabalhos, a autora divide os fatores em três conjuntos, sintetizando as principais proposições de cada um deles. $O$ primeiro conjunto seria formado pelas explicações que privilegiam fatores sistêmicos e/ou ligados à questão do poder (vinculados, em linhas gerais, à perspectiva teórica realista de Relações Internacionais). A partir dessa perspectiva, poderiam ser identificados quatro motivos para a adoção de funções securitárias pelas organizações econômicas: (i) a intenção de evitar a intervenção de potências externas; (ii) o fato de a Organização das Nações Unidas (ONU) e/ou das potências externas não se mostrarem dispostas a realizar intervenções em um contexto de instabilidade; (iii) a intenção de conter uma potência regional; e (iv) a percepção, pelo hegêmona regional, de que haveria uma sobreposição

Guilherme Ziebell de Oliveira - Professor colaborador do Programa de Pós-Graduação em Estudos Estratégicos Internacionais (PPGEEI) da Universidade Federal do Rio Grande do Sul (UFRGS). Doutor em Ciência Política e mestre em Estudos Estratégicos Internacionais 
dos interesses securitários regionais e nacionais, motivando-o a capitanear a transformação da organização regional.

O segundo conjunto agregaria as explicações de natureza funcional e organizacional (próximas às ideias do institucionalismo neoliberal) e permitiria a identificação de cinco motivos para a adoção de funções securitárias pelas organizações regionais: (i) a ideia de que a organização seria o ator com conhecimento e laços mais profundos com os atores regionais, sendo mais eficiente na resolução de crises; (ii) a necessidade de garantir a segurança e a estabilidade para viabilizar seus objetivos econômicos primordiais; (iii) como uma forma de compensar falhas anteriores; (iv) o sucesso dos objetivos econômicos e políticos motivaria uma expansão dos objetivos da organização; e (v) a busca por melhorar sua reputação global. Por fim, o terceiro conjunto seria formado pelas explicações ligadas a fatores sociais e/ou ideacionais (relacionadas à corrente teórica construtivista de Relações Internacionais), e permitira a identificação de seis motivos para a adoção de funções securitárias pelas organizações econômicas regionais: (i) a existência de valores e normas securitárias; (ii) a existência de uma norma cultural regional de responsabilidade pelo vizinho; (iii) a percepção de uma ameaça à própria existência da organização; (iv) a securitização de eventos específicos; (v) o entendimento de que os desafios securitários estão associados a dinâmicas regionais e só podem ser resolvidos nesse nível; e (vi) a existência de uma identidade comum, que faz com que eventuais ameaças a membros da organização sejam percebidas como ameaças a todos.

A partir desse ferramental, Brown constrói estudos de caso de três organizações regionais, nos quais busca testar cada uma das possíveis explicações para a adoção, por elas, de funções securitárias convencionais. Assim, no terceiro capítulo, a autora debruça-se sobre a atuação da Associação das Nações do Sudeste Asiático (ASEAN) diante da guerra cambojana-vietnamita, iniciada em 1979 e que teve como consequência principal, não apenas a incorporação dos dois contendores à organização, mas também a criação, em 1992, do Fórum Regional da ASEAN que, de acordo com Brown, tornou-se a principal organização multilateral de segurança do sudeste asiático. O quarto capítulo é dedicado à análise da atuação da Comunidade Econômica da África Ocidental (ECOWAS) na guerra civil da Libéria, que iniciou em dezembro de 1989, e teve como marca mais significativa a criação do Grupo de Monitoramento da Organização (ECOMOG). Por fim, o quinto capítulo é dedicado à análise da atuação da Comunidade Europeia diante do processo de desintegração da Iugoslávia, em 1990, ressaltando os motivos que levaram a ONU a assumir a responsabilidade pela estabilização do conflito, bem como os desenvolvimentos, no âmbito do processo 
de integração europeu, no sentido de desenvolver ferramentas securitárias de escopo regional mais robustas.

No último capítulo, a autora busca sintetizar as principais conclusões alcançadas no trabalho. Em linhas gerais, o que fica expresso é a identificação de poucas regularidades em termos de motivos que levariam as organizações regionais a buscarem incorporar funções de segurança convencional às suas atribuições. Os três casos analisados teriam em comum apenas a preocupação das organizações regionais em evitar intervenções de atores externos, bem como o entendimento de que as questões securitárias seriam permeadas por dinâmicas regionais, e, portanto, deveriam ser tratadas a partir desse nível. Os demais possíveis elementos motivadores, ou não estariam na origem das transformações das organizações, ou teriam motivado as mudanças em apenas uma ou em duas das organizações.

Por um lado, a obra apresenta uma contribuição interessante, ao ressaltar a capacidade de diferentes vertentes teóricas de apresentarem explicações relevantes para a incorporação, pelas organizações econômicas regionais, de funções de segurança convencional. Por outro, contudo, ela demonstra limitações importantes - fruto, em grande medida, não apenas da brevidade e superficialidade dos estudos de caso apresentados, mas também da falta de rigor nas análises (não há, por exemplo, a apresentação de critérios claros para a avaliação da relevância das possíveis motivações em cada caso). Nesse sentido, parece difícil conceber que a preocupação com a garantia de segurança e estabilidade como pré-requisitos para a consecução de seus objetivos econômicos primordiais não tenha tido grande peso na decisão da Comunidade Europeia de buscar desenvolver uma abordagem securitária comum (como teria havido nos casos da ASEAN e da ECOWAS), ou mesmo que a ASEAN e a ECOWAS, ao incorporarem funções de segurança comum, não tenham buscado melhorar sua reputação internacional (que seria o caso da Comunidade Europeia). Em linhas gerais, portanto, trata-se de uma obra que busca discutir um tema de grande relevância e interesse, mas que tem pouco a contribuir no escopo de sua proposta.

Recebido em 01/04/2020. Aceito para publicação em 02/04/2020. 